\title{
MicroRNA-7 suppresses human colon cancer invasion and proliferation by targeting the expression of focal adhesion kinase
}

\author{
CHUN-YAN ZENG ${ }^{1 *}$, YI-SHAN ZHAN ${ }^{2 *}$, JUN HUANG $^{2}$ and YOU-XIANG CHEN ${ }^{2}$ \\ Departments of ${ }^{1}$ Oncology and ${ }^{2}$ Gastroenterology, The First Affiliated Hospital of Nanchang University, \\ Nanchang, Jiangxi 330006, P.R. China
}

Received November 11, 2014; Accepted August 19, 2015

DOI: $10.3892 / \mathrm{mmr} .2015 .4643$

\begin{abstract}
Previous studies have demonstrated that microRNA (miRNA) are essential in tumor development and invasion. The close association between focal adhesion kinase (FAK) and colon cancer (CC) has been previously reported. miRNA-7 (miR-7) inhibits the translation of FAK protein. Therefore, the present study aimed to assess the underlying molecular mechanism of miR-7 in human CC cell lines, to provide a novel therapeutic biomarker of $\mathrm{CC}$ in the future. The present study detected the expression of miR-7 in $60 \mathrm{CC}$ tissues by reverse transcription-quantitative polymerase chain reaction (RT-qPCR). The association between the expression of miR-7 and clinical pathological factors was analyzed. Overexpression/underexpression of miR-7 were established by transfecting miR-7mimics/inhibitors into HCT-8 and Caco- 2 cells. The transfected CC cell lines were used in cell viability and scratching assays. The regulation of FAK by miR-7 was analyzed by western blotting and RT-qPCR. It was demonstrated that the expression of miR-7 negatively correlated with lymph node metastasis and tumor node metastasis staging in $\mathrm{CC}(\mathrm{P}<0.05)$. Inhibition of miR-7 led to an accelerated ability of proliferation and migration in $\mathrm{CC}$ cell lines. Additionally, overexpression of miR-7 inhibited the proliferation and migration of CC cells. In addition, it was also observed that miR-7 regulated the proliferation and migration of CC by regulating the protein expression of FAK, therefore, regulating the expression of matrix metalloproteinase (MMP)-2 and MMP-9. miR-7 inhibited the proliferation and migration of CC cells by regulating FAK. These findings suggested that miR-7 may be a novel therapeutic target for CC.
\end{abstract}

Correspondence to: $\mathrm{Dr}$ You-Xiang Chen, Department of Gastroenterology, The First Affiliated Hospital of Nanchang University, 17 Yongwaizheng Street, Nanchang, Jiangxi 330006, P.R. China

E-mail: chenyx102@126.com

${ }^{*}$ Contributed equally

Key words: microRNA-7, colon cancer, focal adhesion kinase, proliferation, migration

\section{Introduction}

Colon cancer (CC) is the second leading cause of cancer-associated mortality worldwide (1). Invasion is the most difficult problem when treating $\mathrm{CC}$, however, the molecular mechanism underlying CC invasion remains to be fully elucidated. According to previous data, $10-25 \%$ of patients with CC have been diagnosed with liver metastasis (2-4). The treatments for CC include surgery, chemotherapy, endoscopic stent implant and targeted chemotherapy $(5,6)$. The most difficult problems for the patients with $\mathrm{CC}$ are invasion and metastasis. Early detection and targeted therapy are more practical and important for the treatment of CC.

Focal adhesion kinase (FAK) is predominantly distributed in the cell cytoplasm, and was initially identified in the $\mathrm{v}$-src transfected chicken embryo fibroblast. FAK causes the accumulation and depolymerization of cytoskeleton proteins, therefore, influencing the structures of cell adhesion sites and membrane protrusions to regulate cell activities (7). FAK also promotes the secretion of the matrix metalloproteinases (MMPs), which can damage the extracellular matrix components of the intercellular matrix and basement membrane, therefore, accelerating the growth and invasion of CC cells (8). FAK is involved in breast cancer, $\mathrm{CC}$, prostate cancer and other malignant tumor types $(9,10)$, and is markedly associated with tumor proliferation, apoptosis, adhesion and migration.

MicroRNA (miRNA), a type of highly conserved non-coding RNA, consists of 18-25 nucleotides with endogenous single-stranded RNA. Lee et al (11) identified the first miRNA, let4, in Caenorhabditis elegans in 1993. miRNA (miR)-21 and miR-264 were subsequently identified in vertebrates, flies, worms, viruses and certain plant species. It is estimated that there are $>1,000$ miRNAs in the human genome (12). miRNAs have been demonstrated to be closely associated with tumor growth and metastasis.

Therefore, miRNAs may be targets for cancer diagnosis and treatment (13). miR-7 is important for the growth and metastasis of glioma, breast, ovarian, bladder, gastric, lung, liver and colon cancer (14-20). miR-7 inhibits the invasion of glioma cells by binding to the 3-untranslated region of FAK mRNA, which inhibits the protein translation of FAK, leading to decreased invasion of glioma cells (14).

The present study investigated the expression of miR-7 in $\mathrm{CC}$ tissues and adjacent colon tissues. Additionally, the possible 
correlations of miR-7 and the clinical pathological factors in $\mathrm{CC}$ were determined, illustrating the effects of overexpression or underexpression of miR-7 on the growth and migration of $\mathrm{CC}$ in vitro. These findings may provide novel targets for the treatment of CC.

\section{Materials and methods}

Antibodies and reagents. The $\mathrm{miR}-7 \mathrm{mimic}(\mathrm{miR}-7 \mathrm{~m})$, negative-5'-cy3, miR-7 inhibitor (miR-7i) and the negative control (NC) were purchased from Ribobio Co., Ltd. (Guangzhou, Guangdong, China). Antibodies were purchased as follows: Rabbit monoclonal FAK (1:1,000; Abcam, Cambridge, MA, USA; cat. no. ab40794), rabbit polyclonal anti-MMP-2 (1:1,000; Proteintech Group, Inc., Chicago, IL, USA; cat.no. 10373-2-AP) and rabbit polyclonal anti-MMP-9 (1:1,000; Proteintech Group, Inc.; cat. no. 10375-2-AP), and rabbit polyclonal anti-actin (1:5,000; Santa Cruz Biotechnology, Inc.; cat. no. sc-1616). All antibodies were diluted with phosphate-buffered saline (PBS). Enhanced chemiluminescence western blot detection reagents were purchased from Thermo Fisher Scientific (Rockford, IL, USA). Protease inhibitor cocktail, Lubrol-PX and 3-(4,5-dimethylthiazol-2-yl)-2,5-diphenyltetrazolium bromide (MTT) were purchased from Sigma-Aldrich (St. Louis, MO, USA). An Invitrogen cDNA synthesis kit was purchased from Thermo Fisher Scientific (Carlsbad, CA, USA). All RNA duplexes were chemically synthesized by GenePharma Co., Ltd. (Shanghai, China).

Cell culture and tissue specimens. Human HCT-8 and Caco-2 CC cell lines were obtained from American Type Culture Collection (Rockville, IL, USA). The cells were maintained in Dulbecco's modified Eagle's medium (Gibco Life Technologies, Carlsbad, CA, USA), supplemented with $10 \%$ fetal bovine serum (Gibco Life Technologies) and $100 \mu \mathrm{g} / \mathrm{ml}$ streptomycin (NCPC Hebei Huamin Pharmaceutical Co., Ltd., Hebei, China) in a humid incubator with $5 \% \mathrm{CO}_{2}$ at $37^{\circ} \mathrm{C}$.

Paired $\mathrm{CC}$ samples and adjacent normal colon tissues were obtained from 60 patients who were diagnosed with CC between 2011 and 2012 in the Department of Pathology, The First Affiliated Hospital of Nanchang University (Nanchang, China). No patient received chemotherapy or radiotherapy prior to surgery and patients were diagnosed by clinical pathological staging based on the 2010 American Joint Committee on Cancer criteria (21). All patients provided written informed consent prior to surgery. The detailed clinical pathological information of all patients and their correlation with the expression of miR-7 are summarized in the Table I. The present study was approved by the institutional review board of The First Affiliated Hospital of Nanchang University medical research ethics committee.

Reverse transcription-quantitative polymerase chain reaction (RT-qPCR). The total RNA was isolated using Invitrogen TRIzol reagent (Thermo Fisher Scientific). The RNA was subsequently reverse transcribed into cDNA using the stem-loop reverse transcription primer (Ribobio Co., Ltd.) for miRNA detection. RT was performed using Revert Aid ${ }^{\mathrm{TM}}$ reverse transcriptase (Fermentas, Ontario, Canada) according to the manufacturer's instructions. The cDNA results were quantified by SYBR Premix Ex Taq ${ }^{\mathrm{TM}}$ (Takara Bio., Inc., Otsu, Japan). The mRNA expression levels of miR-7 and FAK were detected by RT-qPCR and analyzed on an Applied Biosystems 7500 PCR Detection system (Applied Biosystems, Inc. Foster City, CA, USA). The mRNA expression levels of miR-7 and FAK were determined and normalized against the expression of U6 using the comparative cycle threshold $(\mathrm{Ct})$ method (22).

Transient transfection of $m i R-7 m$ or $m i R-7 i$. The human HCT- 8 and Caco-2 CC cell lines were cultured in antibiotic-free medium for $48 \mathrm{~h}$ in 6 -well plates. Upon reaching a confluence of $60-70 \%$, the miR-7m (50 nM), miR-7i (300 $\mathrm{mM})$, unrelated sequence positive control $(50 \mathrm{nM})$ or the $\mathrm{NC}(300 \mathrm{nM})$ were transfected into the cells using an Invitrogen Lipofectamine 2000 reagent (Thermo Fisher Scientific), according to the manufacturer's instructions.

Protein extraction and western blotting. Following incubation for $72 \mathrm{~h}$ after transfection with miR-7m, miR-7i or the control, the cells were washed with cold PBS three times and were subsequently resuspended in protein lysis buffer (Beyotime Institute of Biotechnology, Haimen, China) at $4^{\circ} \mathrm{C}$ for $30 \mathrm{~min}$. The protein concentrations were measured following centrifugation and quantified using the bicinchoninic acid assay kit (Beyotime Institute of Biotechnology). A Bio-Rad Model 680 microplate reader (Bio-Rad Laboratories, Inc., Hercules, CA, USA) was used to measure the results of the assay. An equal quantity of protein was separated on $8 \%$ SDS-PAGE gels (Sigma-Aldrich) and transferred onto polyvinylidene difluoride membranes (EMD Millipore, Billerica, MA, USA). The membranes were blocked with $50 \mathrm{mg} / \mathrm{ml}$ non-fat milk in $10 \mathrm{ml}$ PBS for $2 \mathrm{~h}$ at room temperature and were subsequently incubated overnight at $4^{\circ} \mathrm{C}$ with the appropriate primary antibody. The membranes were washed with PBS and incubated with horseradish peroxidase-conjugated goat anti-rat immunoglobulin (Ig)G/IgM (cat. no. AP132P; 1:1,000; Merck Millipore, Darmstadt, Germany) at $4^{\circ} \mathrm{C}$ for $4 \mathrm{~h}$. The images were captured and quantified using Gel Doc XR-Z system (controlled by Image Lab $^{\mathrm{TM}}$ version 2.0; (Bio-Rad Laboratories, Inc.).

Cell viability analysis. A cell viability assay was performed on the CC cells using an MTT reduction assay (23). The cells were seeded into 96 -well plates for $24 \mathrm{~h}$ and were subsequently transfected with miR-7m/i. At 24, 48 and $72 \mathrm{~h}$ after transfection, $20 \mu \mathrm{l}$ MTT reagent $(5 \mathrm{mg} / \mathrm{ml})$ was added to each well for $4 \mathrm{~h}$ at $4^{\circ} \mathrm{C}$. The generated formazan product was dissolved in $150 \mu 1$ dimethyl sulfoxide. The optical density at $490 \mathrm{~nm}$ was measured using the Bio-Rad Model 680 microplate reader. Triplicate wells were used for each cell line and experiments were repeated in triplicate.

Wound healing assay. Cell migration was measured using a wound healing assay. The HCT- 8 and Caco- 2 cells (3x10 $/$ well) were seeded into 6 -well plates. Once the cells reached a confluence between 90 and $100 \%$ at $48-72 \mathrm{~h}$ after transfection, a $10-\mu 1$ pipette tip was used to scrape the cell monolayer. Fresh serum-free medium was added and images 
Table I. Correlation between the expression of miR-7 and clinical pathological characteristics in colon cancer.

\begin{tabular}{|c|c|c|c|c|}
\hline Characteristic & Cases (n) & miR-7 expression ${ }^{\mathrm{b}}$ & Spearman's (R) & P-value \\
\hline \multicolumn{5}{|l|}{ Gender } \\
\hline Male & 29 & $0.38(0.11-2.27)$ & \multirow{2}{*}{-0.726} & \multirow{2}{*}{0.773} \\
\hline Female & 31 & $0.58(014-2.01)$ & & \\
\hline \multicolumn{5}{|l|}{ Age (years) } \\
\hline$<60$ & 28 & $0.44(0.15-2.56)$ & \multirow{2}{*}{-1.089} & \multirow{2}{*}{0.276} \\
\hline$\geq 60$ & 32 & $0.49(0.10-1.71)$ & & \\
\hline \multicolumn{5}{|c|}{ Histopathologic differentiation } \\
\hline WD/MD & 36 & $0.35(0.12-1.97)$ & \multirow{2}{*}{-0.800} & \multirow{2}{*}{0.424} \\
\hline PD/UD & 24 & $0.49(0.13-1.29)$ & & \\
\hline \multicolumn{5}{|c|}{ Lymph node metastasis } \\
\hline Yes & 27 & $0.19(0.09-1.16)$ & \multirow{2}{*}{-2.290} & \multirow{2}{*}{$0.022^{\mathrm{a}}$} \\
\hline No & 33 & $0.69(0.27-2.23)$ & & \\
\hline \multicolumn{5}{|l|}{ TNM staging } \\
\hline $\mathrm{I}+\mathrm{II}$ & 30 & $0.75(0.30-2.32)$ & \multirow{2}{*}{-2.698} & \multirow{2}{*}{0.007} \\
\hline III+IV & 30 & $0.17(0.09-1.23)$ & & \\
\hline
\end{tabular}

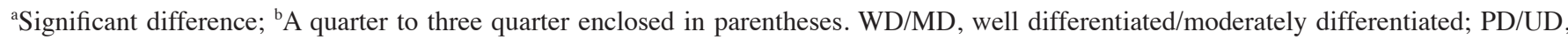
poorly differentiated/undifferentiated; miR, microRNA; TNM, tumor node metastasis.

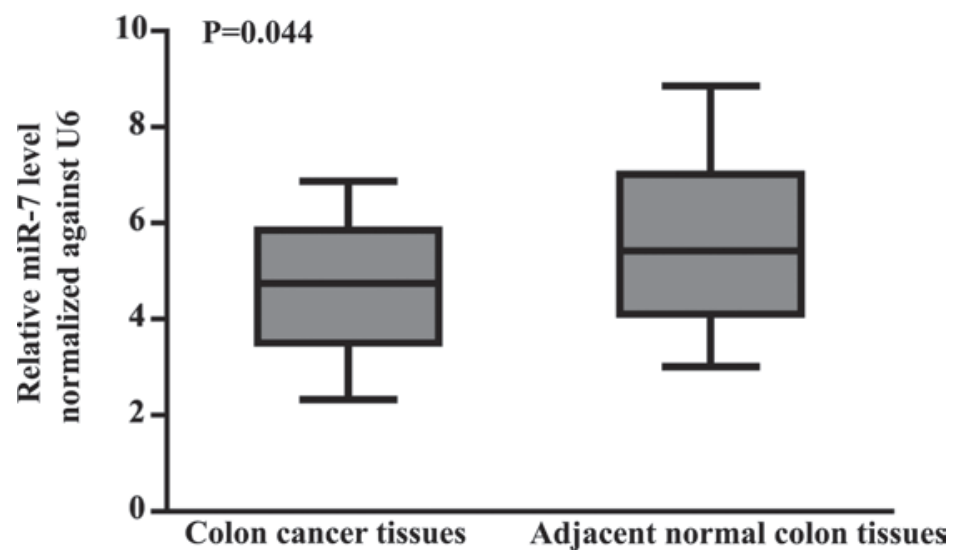

Figure 1. Expression of miR-7 in colon cancer. The expression level of miR-7 in colon cancer and adjacent normal colon tissues ( $\mathrm{n}=60$ ) was determined using reverse transcription-quantitative polymerase chain reaction. The expression levels of miR-7 are demonstrated as box plots, normalized against the levels of U6. The error bars represent a $95 \%$ confidence interval. miR, microRNA.

were captured at 0,24 and $48 \mathrm{~h}$ after wounding using a phase contrast microscope (IX711; Olympus, Tokyo, Japan). The wound-healing areas were first compared to the wound area at $0 \mathrm{~h}$, and were finally compared to the mock control using Image J $1.48 \mathrm{u}$ software (National Institutes of Health, MA, USA).

Statistical analysis. All data were analyzed using SPSS 17.0 software (SPSS, Inc., Chicago, IL, USA). The data are presented as the mean \pm standard deviation. The differences between the groups were assessed by Student's t-test or one-way analysis of variance. Pearson's correlation coefficient was used to assess the correlation between the expression levels of FAK and miR-7 in CC. $\mathrm{P}<0.05$ was considered to indicate a statistically significant difference.

\section{Results}

miR-7 is downregulated in CC and correlates with clinical significance. A total of 60 cases of fresh specimens of $\mathrm{CC}$ and adjacent normal colon tissues were used to detect the expression of miR-7 by RT-qPCR. The expression of miR-7 was markedly downregulated in CC compared with paired normal colon tissues $(\mathrm{P}=0.044$; Fig. 1$)$. As shown in Table I, the expression of miR-7 negatively correlated with lymph node metastasis $(\mathrm{r}=-2.29 ; \mathrm{P}=0.022)$ and tumor node metastasis $(\mathrm{TNM})$ stages $(\mathrm{r}=-2.698 ; \mathrm{P}=0.007)$, regardless of gender, age and histopathologic differentiation of the patients with CC. These results suggested that miR-7 may be a potential tumor suppressor and may be important in the development of CC. 
A
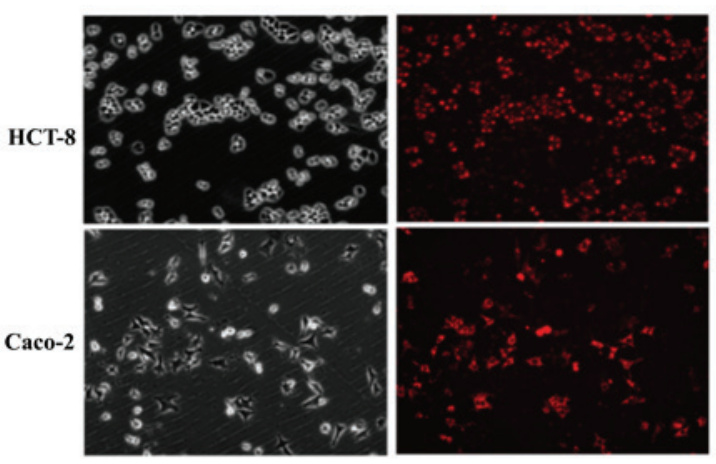

B

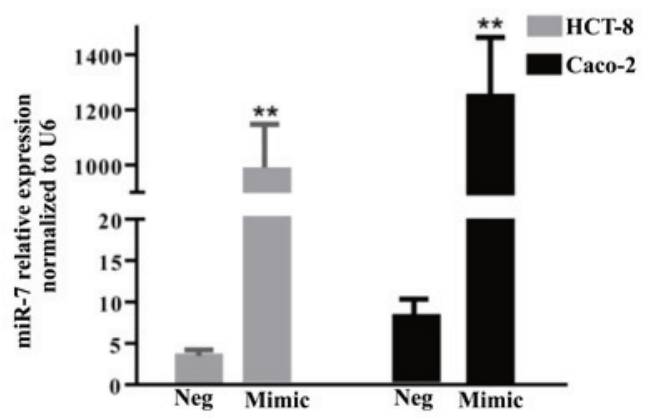

D

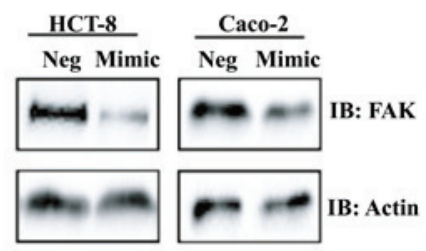

$\mathbf{F}$

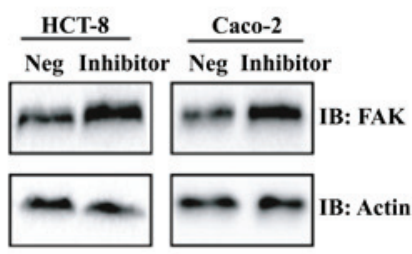

C

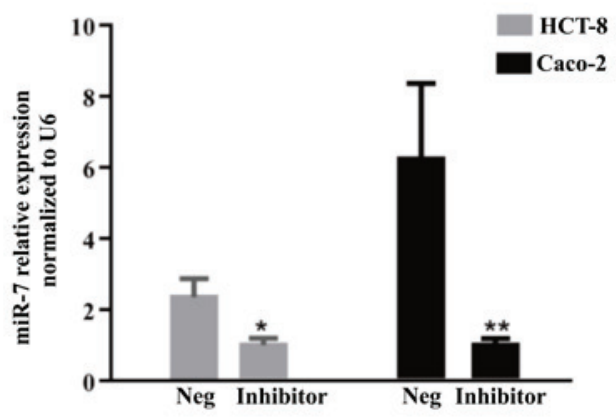

$\mathbf{E}$

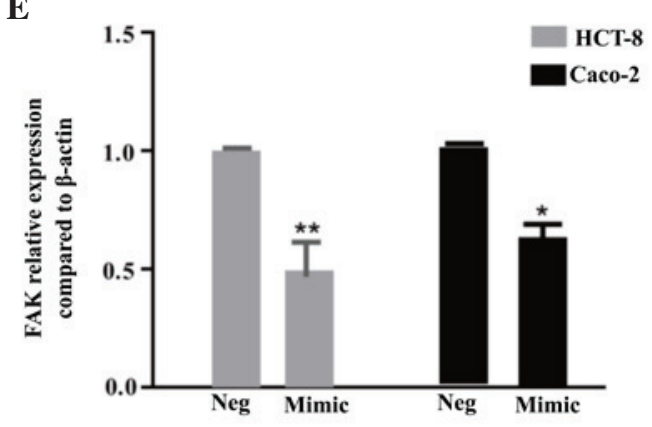

G

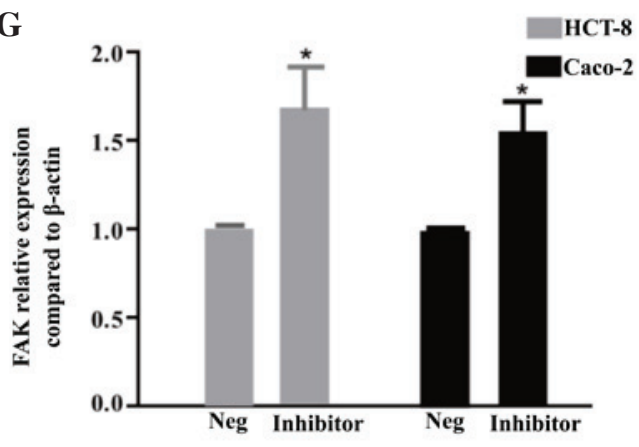

Figure 2. Alteration of the expression of miR-7 changed the protein expression of FAK. (A) Fluorescence images of Caco-2 and HCT-8 cells treated with the miR-7 mimic, negative-5'-cy3. The expression of miR-7 in HCT-8 and Caco-2 cells treated with (B) miR-7 mimic or (C) miR-7 inhibitor was determined by reverse transcription-quantitative polymerase chain reaction. (D) The expression of FAK was detected in HCT-8 and Caco-2 cells following transfection with the miR-7 mimic by western blotting. (E) Histograms illustrate the expression of FAK following transfection with the miR-7 mimic. The data are expressed as the mean \pm standard deviation of three independent experiments ( ${ }^{*} \mathrm{P}<0.05$ and ${ }^{* *} \mathrm{P}<0.01$, compared with the Neg cells). (F) The expression of FAK was detected in HCT-8 and Caco-2 cells following transfection with the miR-7 inhibitor by western blotting. (G) Histograms illustrate the expression of FAK following transfection with the miR-7 inhibitor. The data are expressed as the mean \pm standard deviation of three independent experiments $\left({ }^{*} \mathrm{P}<0.05\right.$ and ${ }^{* *} \mathrm{P}<0.01$, compared with the Neg cells). FAK, focal adhesion protein; Neg, negative control; miR, microRNA; IB, immunoblotting.

Expression of miR-7 is associated with the protein expression of FAK. To further determine whether FAK was a downstream target of miR-7, miR-7m, miR-7i or NC were transfected into Caco- 2 and HCT- 8 cells. To confirm the transfection efficiency, fluorescence images were caputred $6 \mathrm{~h}$ after transfection using miR-7m, negative-5'-cy3 (Fig. 2A). Compared with the NC or mock, the expression of miR-7 was significantly increased or decreased following transfection with miR-7m or miR-7i, respectively in the HCT-8 and Caco-2 cells (Fig. 2B and C). The ectopic expression of miR-7 significantly decreased the protein expression of FAK, as determined by western blotting $(\mathrm{P}<0.05$; Fig. 2D and E). However, a decrease in the expression 
A

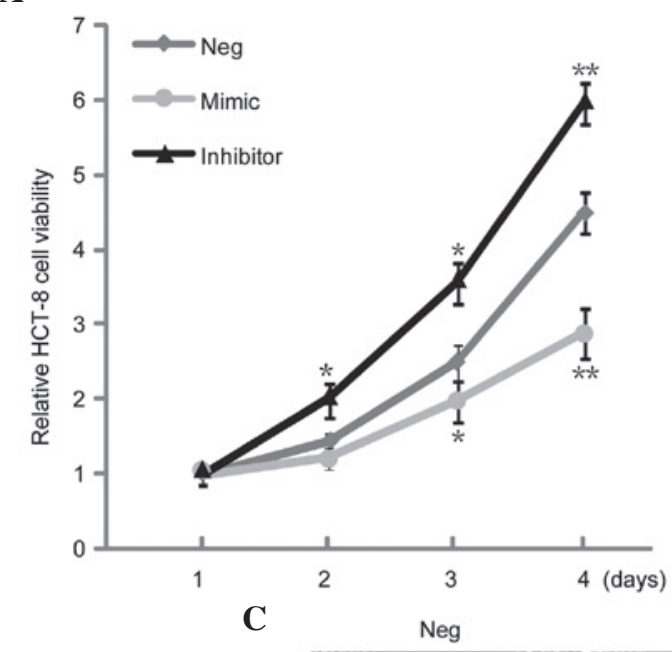

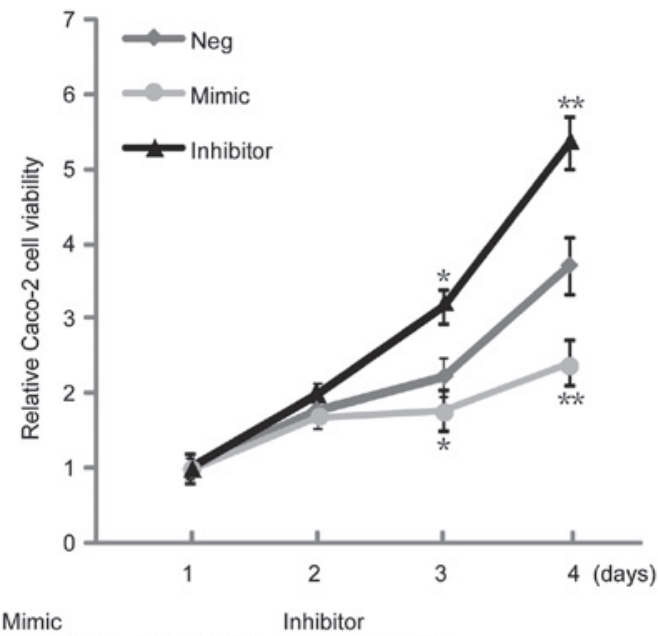

$\mathrm{Oh}$
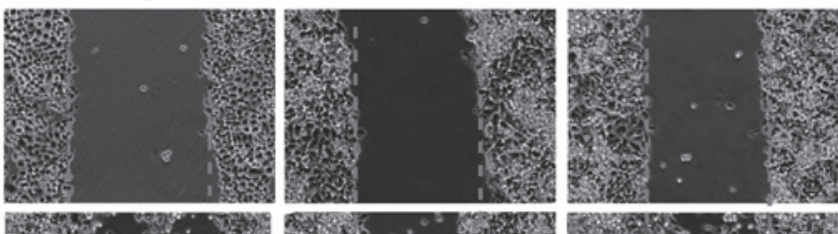

$48 \mathrm{~h}$
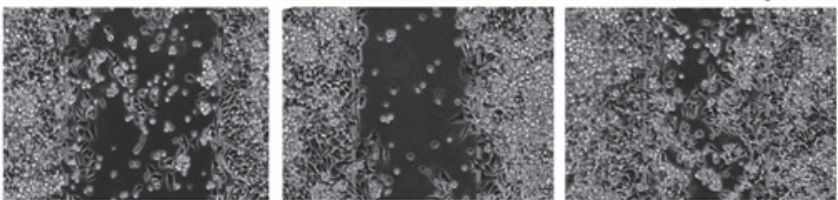

D

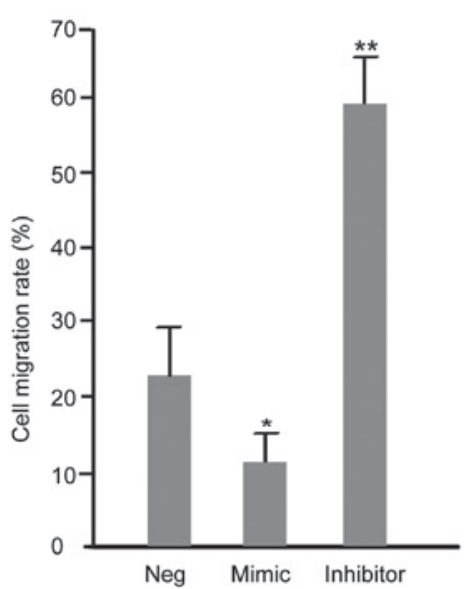

Figure 3. miR-7 suppresses the migration and proliferation of colon cancer cells. (A and B) Repression of miR-7 enhances the viability of colon cancer cells. Decreased viability was observed in gastric cancer cells transfected with miR-7 mimic. The cell viabilities of (A) HCT-8 and (B) Caco-2 cells were assessed by an MTT assay. The data are expressed as the mean \pm standard deviation of three independent experiments $\left({ }^{*} \mathrm{P}<0.05\right.$ and ${ }^{* *} \mathrm{P}<0.01$, compared with the Neg cells). (C and D) The migration of HCT-8 cells was reduced following transfection with miR-7 mimic, however, the repression of miR-7 accelerated the migration of HCT- 8 cells, as determined by a wound healing assay. The data are expressed as the mean \pm standard deviation of three independent experiments $($ P $<0.05$ and ${ }^{* *} \mathrm{P}<0.01$, compared with the Neg cells). Neg, negative control; miR, microRNA.

A

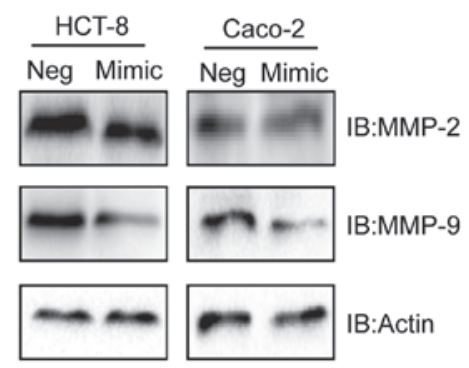

B

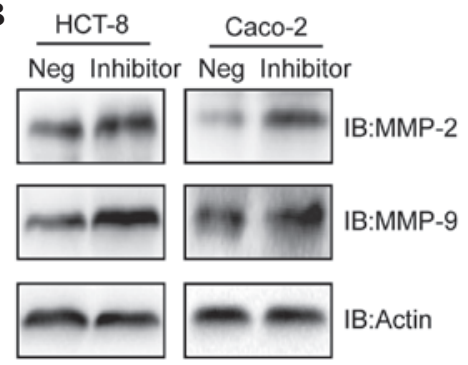

Figure 4. Effects of miR-7 on the MMP-2/MMP-9 pathway. (A) The expression levels of MMP2/MMP9 in HCT-8 and Caco-2 cells treated with the miR-7 mimic were determined by western blotting. (B) The expression levels of MMP2/MMP9 in HCT-8 and Caco-2 cells treated with miR-7 inhibitor were determined by western blotting. miR, microRNA; MMP, matrix metalloproteinase. 
of miR-7 led to increased protein expression of FAK $(\mathrm{P}<0.05$; Fig. 2F and G).

miR-7 influences the proliferation and migration of CC cells. The effect of miR-7 on the proliferation and migration of CC cells was assessed by a wound healing and MTT assay, respectively. It was revealed that the upregulation of miR-7 inhibited the proliferation and migration of HCT-8 cells (Fig. 3A and B). Additionally, downregulation of miR-7 enhanced the proliferation and migration of HCT-8 and Caco-2 cell lines (Fig. 3C and D).

miR-7 correlates with the expression levels of MMP-2 and $M M P$-9. Additionally, to investigate the mechanism underlying how miR-7 influences the biological behavior of CC cell lines, the levels of the invasion factors, MMP-2 and MMP-9, were assessed by western blotting following the up/downregulation of miR-7. Notably, it was revealed that the protein expression levels of MMP-2 and MMP-9 were significantly decreased/increased when HCT- 8 and Caco- 2 cells were transfected with $\mathrm{miR}-7 \mathrm{~m} / \mathrm{i}$, respectively, as determined by western blotting (Fig. 4A and B).

\section{Discussion}

The incidence of $\mathrm{CC}$ revealed an increasing trend with recurrent cases causing liver metastasis (24). Previous studies suggested that metastasis is the predominant reason for the high mortality-associated with CC. In the human gene bank, $>1,000$ types of miRNAs are reported. Accumulating evidence suggested that miRNAs are important in CC tumorigenesis (25). At present, the correlation of CC with miRNAs remains to be elucidated. Balaguer et al (26) revealed that miR-137 acted as a tumor suppressor, however, was frequently silenced by promoter hypermethylation in colorectal carcinoma (CRC). Kulda et al (27) observed a higher expression of miR-21 and lower expression of miR-143 in CRC compared with adjacent normal colon tissue samples, which was associated with liver metastasis of CRC. Yamakuchi et al (28) suggested that miR-107 mediates the regulation of p53 on the hypoxic signaling and tumor angiogenesis pathways.

miR-7 is a member of the miRNA family, and is located on chromosome 15. The expression of miR-7 differs in various tumor types (29). Xiong et al (17) revealed that increased expression of miR-7 inhibits cell growth and invasion in the human A529 non-small cell lung cancer cell line. Notably, similar findings were observed in malignant glioma and schwannoma $(30,31)$. FAK is a crucial signaling component and functions as a biosensor or integrator to control cell motility. Previous studies revealed that FAK, particularly phosphorylated (p)-FAK (Y397), was highly expressed in multiple tumor types, and was closely associated with the invasion and metastasis of the tumor (32). How FAK and its signaling pathway regulate the development of $\mathrm{CC}$ remains to be elucidated. Currently, research on FAK inhibitors is being performed to target its Y397 phosphorylation, for example, p-FAKY397 antibodies or FAK-related non-kinase (33), however the treatment remains limited. Whether there are more targets to control the invasion of $\mathrm{CC}$ by inhibiting the expression of FAK remains to be elucidated.
For the above issues, the present study aimed to investigate the effect of miR-7 on the biological behavior of CC and the correlation with FAK, which proved to be a promising target for the treatment and prognosis of CC.

Firstly, the present study revealed that the expression of miR-7 was decreased in CC tissues compared with the paired adjacent normal tissues, by RT-qPCR, and this correlated with lymph node metastasis and TNM stages in CC. Next, the expression of miR-7 was investigated in vitro and revealed that miR-7 inhibited the proliferation and invasiveness in CC cell lines using MTT and wound healing assays, respectively. Finally, it was revealed that the protein expression levels of FAK, MMP-2 and MMP-9 were significantly reduced following transfection with the miR-7m, however, increased following transfection with the miR-7i in CC cell lines.

These results were consistent with the results of a previous study revealing that miR-7 inhibited the growth and metastasis of glioma by targeting a negative regulator of FAK (14). miR-7 inhibited the epithelial-mesenchymal transition to suppress the growth and metastasis of breast cancer by targeting the protein expression of FAK (34).

In conclusion, the present study revealed that miR-7 suppressed the growth and proliferation of CC cell lines by targeting FAK. Notably, the present study provided novel insights into the mechanisms underlying tumor growth and metastasis. miR-7 may be a potential therapeutic strategy for the treatment of $\mathrm{CC}$ in the future.

\section{Acknowledgements}

The present study was supported by grants from the Natural Science Foundation of Jiangxi Province (grant no. 20142BAB205054) and the Post-graduates Innovation Foundation of Jiangxi Province (grant no. YC2011-B007).

\section{References}

1. Jemal A, Center MM, DeSantis C and Ward EM: Global patterns of cancer incidence and mortality rates and trends. Cancer Epidemiol Biomarkers Prev 19: 1893-1907, 2010.

2. Cunningham D, Atkin W, Lenz HJ, Lynch HT, Minsky B, Nordlinger B and Starling N: Colorectal cancer. Lancet 375: 1030-1047, 2010.

3. Chen W, Zheng R, Zhang S, Zhao P, Zeng H, Zou X and He J: Annual report on status of cancer in China, 2010. Chin J Cancer Res 26: 48-58, 2014.

4. Jemal A, Bray F, Center MM, Ferlay J, Ward E and Forman D: Global cancer statistics. CA Cancer J Clin 61: 69-90, 2011.

5. Cromheecke M, de Jong KP and Hoekstra HJ: Current treatment for colorectal cancer metastatic to the liver. Eur J Surg Oncol 25: 451-463, 1999.

6. Warden C, Stupart D and Goldberg P: Stenting as first-line management for all patients with nonperforating left-sided obstructing colorectal cancer. Colorectal Dis 15: e389-e395, 2013.

7. Mitra SK, Hanson DA and Schlaepfer DD: Focal adhesion kinase: In command and control of cell motility. Nat Rev Mol Cell Biol 6: 56-68, 2005.

8. Sein TT, Thant AA, Hiraiwa Y, Amin AR, Sohara Y, Liu Y, Matsuda S, Yamamoto T and Hamaguchi M: A role for FAK in the Concanavalin A-dependent secretion of matrix metalloproteinase-2 and -9. Oncogene 19: 5539-5542, 2000.

9. Cance WG, Harris JE, Iacocca MV, Roche E, Yang X, Chang J, Simkins S and Xu L: Immunohistochemical analyses of focal adhesion kinase expression in benign and malignant human breast and colon tissues: Correlation with preinvasive and invasive phenotypes. Clin Cancer Res 6: 2417-2423, 2000. 
10. Rovin JD, Frierson HF Jr, Ledinh W, Parsons JT and Adams RB: Expression of focal adhesion kinase in normal and pathologic human prostate tissues. Prostate 53: 124-132, 2002.

11. Lee RC, Feinbaum RL and Ambros V: The C. elegans heterochronic gene lin-4 encodes small RNAs with antisense complementarity to lin-14. Cell 75: 843-854, 1993.

12. Garzon R, Calin GA and Croce CM: MicroRNAs in cancer. Annu Rev Med 60: 167-179, 2009.

13. Calin GA and Croce CM: MicroRNA signatures in human cancers. Nat Rev Cancer 6: 857-866, 2006.

14. Wu DG, Wang YY, Fan LG, Luo H, Han B, Sun LH, Wang XF, Zhang JX, Cao L, Wang XR, et al: MicroRNA-7 regulates glioblastoma cell invasion via targeting focal adhesion kinase expression. Chin Med J (Engl) 124: 2616-2621, 2011.

15. Fang Y, Xue JL, Shen Q, Chen J and Tian L: MicroRNA-7 inhibits tumor growth and metastasis by targeting the phosphoinositide 3-kinase/Akt pathway in hepatocellular carcinoma. Hepatology 55: 1852-1862, 2012.

16. Reddy SD, Ohshiro K, Rayala SK and Kumar R: MicroRNA-7, a homeobox D10 target, inhibits p21-activated kinase 1 and regulates its functions. Cancer Res 68: 8195-8200, 2008.

17. Xiong S, Zheng Y, Jiang P, Liu R, Liu X and Chu Y: MicroRNA-7 inhibits the growth of human non-small cell lung cancer A549 cells through targeting BCL-2. Int J Biol Sci 7: 805-814, 2011.

18. Zhao X, Dou W, He L, Liang S, Tie J, Liu C, Li T, Lu Y, Mo P, Shi Y, et al: MicroRNA-7 functions as an anti-metastatic microRNA in gastric cancer by targeting insulin-like growth factor-1 receptor. Oncogene 32: 1363-1372, 2013

19. Zhang N, Li X, Wu CW, Dong Y, Cai M, Mok MT, Wang H, Chen J, Ng SS, Chen M, et al: microRNA-7 is a novel inhibitor of YY1 contributing to colorectal tumorigenesis. Oncogene 32: 5078-5088, 2013

20. Luo J, Cai Q, Wang W, Huang H, Zeng H, He W, Deng W, Yu H, Chan E, Ng CF, et al: A microRNA-7 binding site polymorphism in HOXB5 leads to differential gene expression in bladder cancer. PLoS One 7: e40127, 2012.

21. Chan KK, Dassanayake B, Deen R, Wickramarachchi RE, Kumarage SK, Samita S and Deen KI: Young patients with colorectal cancer have poor survival in the first twenty months after operation and predictable survival in the medium and long-term: Analysis of survival and prognostic markers. World J Surg Oncol 8: 82, 2010.

22. Schmittgen TD and Livak KJ: Analyzing real-time PCR data by the comparative C(T) method. Nat Protoc 3: 1101-1108, 2008 .
23. Bannazadeh Amirkhiz M, Rashtchizadeh N, Nazemieh H, Abdolalizadeh J, Mohammadnejad L and Baradaran B: Cytotoxic effects of alcoholic extract of dorema glabrum seed on cancerous cells viability. Adv Pharm Bull 3: 403-408, 2013.

24. Maruta M and Maeda K: Trends in the treatment for liver metastasis of colorectal cancer in Japan. Rozhl Chir 90: 669-673, 2011.

25. Esquela-Kerscher A and Slack FJ: Oncomirs-microRNAs with a role in cancer. Nat Rev Cancer 6: 259-269, 2006

26. Balaguer F, Link A, Lozano JJ, Cuatrecasas M, Nagasaka T, Boland CR and Goel A: Epigenetic silencing of miR-137 is an early event in colorectal carcinogenesis. Cancer Res 70: 6609-6618, 2010

27. Kulda V, Pesta M, Topolcan O, Liska V, Treska V, Sutnar A, Rupert K, Ludvikova M, Babuska V, Holubec L Jr and Cerny R: Relevance of miR-21 and miR-143 expression in tissue samples of colorectal carcinoma and its liver metastases. Cancer Genet Cytogenet 200: 154-160, 2010.

28. Yamakuchi M, Lotterman CD, Bao C, Hruban RH, Karim B, Mendell JT, Huso D and Lowenstein CJ: P53-induced microRNA-107 inhibits HIF-1 and tumor angiogenesis. Proc Natl Acad Sci USA 107: 6334-6339, 2010.

29. Foekens JA, Sieuwerts AM, Smid M, Look MP, de Weerd V, Boersma AW, Klijn JG, Wiemer EA and Martens JW: Four miRNAs associated with aggressiveness of lymph node-negative, estrogen receptor-positive human breast cancer. Proc Natl Acad Sci USA 105: 13021-13026, 2008.

30. Saydam O, Senol O, Wurdinger T, Mizrak A, Ozdener GB, Stemmer-Rachamimov AO, Yi M, Stephens RM, Krichevsky AM, Saydam N, et al: miRNA-7 attenuation in Schwannoma tumors stimulates growth by upregulating three oncogenic signaling pathways. Cancer Res 71: 852-861, 2011.

31. Kefas B, Godlewski J, Comeau L, Li Y, Abounader R, Hawkinson M, Lee J, Fine H, Chiocca EA, Lawler S and Purow B: microRNA-7 inhibits the epidermal growth factor receptor and the Akt pathway and is down-regulated in glioblastoma. Cancer Res 68: 3566-3572, 2008.

32. Liu TJ, LaFortune T, Honda T, Ohmori O, Hatakeyama S, Meyer T, Jackson D, de Groot J and Yung WK: Inhibition of both focal adhesion kinase and insulin-like growth factor-I receptor kinase suppresses glioma proliferation in vitro and in vivo. Mol Cancer Ther 6: 1357-1367, 2007.

33. Lacoste J, Aprikian AG and Chevalier S: Focal adhesion kinase is required for bombesin-induced prostate cancer cell motility. Mol Cell Endocrinol 235: 51-61, 2005.

34. Kong X,Li G, Yuan Y,He Y,Wu X, Zhang W, Wu Z, Chen T, Wu W, Lobie PE and Zhu T: MicroRNA-7 inhibits epithelial-to-mesenchymal transition and metastasis of breast cancer cells via targeting FAK expression. PLoS One 7: e41523, 2012. 